\title{
Adverse drug reactions of anti-infective drugs for systemic use in Morocco: Pharmaco-Epidemiological study 2008-2016
} \author{
Abdelrhani Mokhtari ${ }^{1}$, Rachida Soulaymani Bencheikh ${ }^{2,3}$ \\ ${ }^{1}$ Laboratory of Genetics and Biometrics, Faculty of sciences, Ibn Tofail University, kénitra, Morocco. \\ ${ }^{2}$ Moroccan Anti-Poison and Pharmacovigilance Center (MAPPC), Rabat, Morocco. \\ ${ }^{3}$ Mohammed V University, Rabat, Morocco.
}

Donia Kharbouch ${ }^{1}$, Houda Sefiani ${ }^{1,2}$, Zineb Nabih ${ }^{1}$, Sanou Khô Coulibaly, Tidiane Diallo, Abdelmajid Soulaymani ${ }^{1}$,

\begin{abstract}
Analyzing the spontaneous reports of adverse drug reactions (ADRs) of anti-infective drugs for systemic use is an essential pillar in creating valuable database in pharmacovigilance. Therefore, the main of this study is to describe the epidemiological and clinical properties, as well as, the frequency and profile of ADRs generated by anti-infective treatment, declared at the Moroccan AntiPoison and Pharmacovigilance Center (MAPPC).A retrospective descriptive study was implemented from the notifications of ADRs generated between 2008 and 2016 and recorded on VIGIBASE. Over the research period, 1161 cases of ADRs reports were declared . The average age was 37.4 years \pm 19.52 , it's been noticed that the adults were the most affected in $81.89 \%$ of the total cases, with the sex ratio (Female / Male) being 1.34. Antimycobacterials and antibacterials for systemic use were responsible for $68 \%$ and $28.3 \%$ of the adverse reactions, respectively. $29.76 \%$ of the cases showcased skin and subcutaneous tissue disorders and $23.23 \%$ of the cases displayed hepatobiliary and pancreatic system disorders. Serious cases represented $30 \%$ of all noted cases, including 2 fatalities.In the interest of preventing the risk of adverse reactions originating from the taking anti-infective drugs for systemic use, reporting to the ADRs to the pharmacovigilance system should be highly encouraged. Keywords:Adverse drug reactions, Pharmacovigilance, antiinfective drugs for systemic use, Antibiotics, Morocco, MAPPC.
\end{abstract}

\section{Introduction}

One of the most universally used drugs in the entire human medicine is the anti-infective drugs for systemic use [1]. It has completely revolutionized the prognosis of bacterial infective pathologies. Nevertheless, this therapeutic section can cause, like any other medicine, adverse drug reactions (ADRs) that can be linked to the inherent activity of the product or its use. Furthermore, the risks related to the improper use of these molecules are acknowledged by the whole medical community [2]. Statistically speaking, anti-infective drugs are the main group that causes adverse drug reactions worldwide [3]. In fact, numerous antibiotics, most notably fluoroquinolones, have been withdrawn from the market in recent years due to the occurrence of rare or exceptional side effects and potentially threatening the lives of patients [4]. In another study, Anti-infective drugs for systemic use specifically the class of Antibacterials for systemic use were the most reported as a cause of ADRs [5].

That's why, it is imperative to monitor the safety of these anti-infectives, whence, the role of pharmacovigilance, which collects the reports of adverse side effects attributed to the drug, thereby generating a signal and highlighting risk factors [6].

Accordingly, the purpose of this work is to implement a retrospective descriptive study of the epidemiological, clinical and progressive characteristics of ADRs cases treated with anti-infective medication, declared at the Moroccan Anti Poison and Pharmacovigilance Center (MAPPC).

\footnotetext{
* Donia Kharbouch : kharbouch.donia@uit.ac.ma
} 


\section{Material and Methods}

During the period spanning from 2008 to 2016 a retrospective descriptive inquiry has been executed using the ADRs of Anti-infective drugs for systemic use recorded on Vigibase (the international pharmacovigilance database of the World Health Organization) which have been reported to the Moroccan Anti-Poison and Pharmacovigilance center.

The adopted age groups depicted in table (1) were those of the WHO International Program on Chemical Safety (IPCS) [6].

Table 1: The adopted age groups for the study

\begin{tabular}{|c|c|}
\hline Age group & Age \\
\hline Newborn & {$[0$ to 0.077 years [} \\
\hline Infant & {$[4$ weeks $(0.078$ years $)-12$ months [} \\
\hline Toddler & {$[1-5$ years old [} \\
\hline Teenager & {$[15-19$ years old [} \\
\hline Adult & {$[19-75$ years old [} \\
\hline Elderly & {$[\geq 75$ years old [} \\
\hline
\end{tabular}

The anti-infective for systemic use, the designation is based on the anatomical, therapeutic and chemical properties (ATC).

The adverse drug reactions are expressed by the standardized medical terminology: MedDRA (Medical Dictionary for Regulatory Activities, according to the hierarchical level System Organ Classes (SOC)) and they're classified according to:

- their severity,

- the affected organ;

- The patient's health status.

The adopted methodology is based on a statistical description of the studied sample that focuses on the characteristics of the concerned population along with the particularities of the involved anti-infective drug and ADRs generated by it. The results were conveyed as a percentage for the qualitative variables and as an average \pm the standard deviation for the quantitative variables.
Frequencies were calculated in order to depict the studied characteristics. Adjustment to the chi-square statistic was used for testing the equality of proportions of different qualitative variables. $\mathrm{P}$ values of 0.05 or less were considered to indicate statistical significance. [8]

\section{Results}

Over the inquiry period, 1160 cases of ADRs' reports of anti-infective drugs for systemic use were collected. (It's important to mention that not all cases from the total of $(\mathrm{N}=1160)$ have listed the "year" or other factors when ADRs took place so we represented the ones that did with " $n$ "). When examining, we found that the highest number of the cases was registered in 2015 (as seen in Figure 1), with a frequency of $49.42 \%$. In regards to the patient sex ratio, it was 1.34 in favor of the female sex.

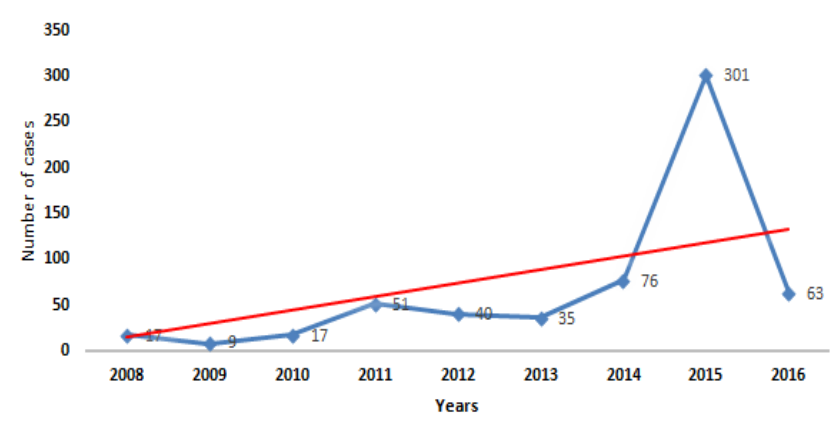

Figure 1: Distribution of the cases $(n=609 / 1160)$ according to the years

As for the age distribution of the studied cases, the average age was 37.4 years \pm 19.52 and the adults were the most affected with $81.89 \%$ of the cases (as observed in Figure 2). It must be borne in mind that in $90 \%$ of the time the route of administration was oral.

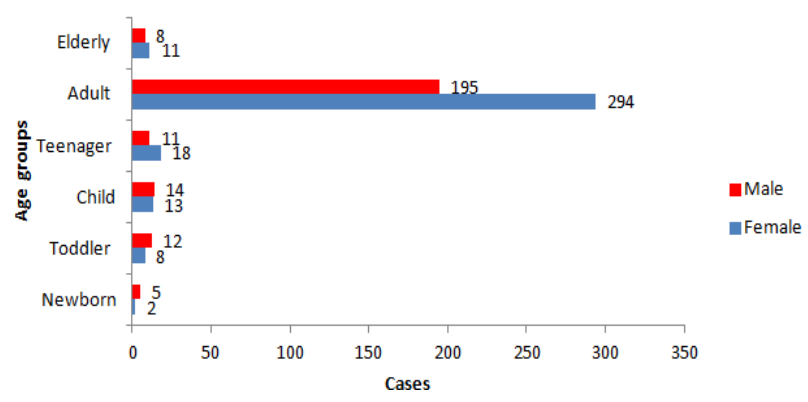


Figure 2: Distribution of the cases $(n=591 / 1160)$ by age and sex. $(\mathrm{P}<0.0001)$

According to table (2), antimycobacterials (J04) were the most disclosed with a frequency of $68.02 \%$. In terms of Antimycotics for systemic use (J02) and vaccines (ATC J07) they were the least represented with $1.81 \%$ and $0.17 \%$ respectively.

Table 2: Distribution of cases according to the involved antiinfective drugs for systemic use $(\mathrm{p}<0.0001)$

\begin{tabular}{|l|c|c|}
\hline \multicolumn{1}{|c|}{ ATC Class } & Cases & $\begin{array}{c}\text { Percentage } \\
\mathbf{( \% )}\end{array}$ \\
\hline $\begin{array}{l}\text { Antibacterials for } \\
\text { systemic use (J01) }\end{array}$ & 329 & 28.36 \\
\hline $\begin{array}{l}\text { Antimycotics for } \\
\text { systemic use (J02) }\end{array}$ & 19 & 1.64 \\
\hline $\begin{array}{l}\text { Antimycobacterials } \\
\text { (J04) }\end{array}$ & 789 & 68.02 \\
\hline $\begin{array}{l}\text { Antivirals for systemic } \\
\text { use (J05) }\end{array}$ & 21 & 1.81 \\
\hline Vaccines (J07) & 1160 & 100.00 \\
\hline Total & 2 & 0.17 \\
\hline
\end{tabular}

The average number of administered drugs was 1.81 and $2 \%$ of the subjects were taking more than one medication at the same time. Of all the disclosed ADRs, 10 anti-infective drugs for systemic use were incriminated by concomitant use, three had poorly interacted with other drugs and 1,146 were subject to direct suspicion owing to their unique treatment.

Among $90 \%$ of the noted ADRs; $29.76 \%$ of the cases presented skin and subcutaneous tissue disorders, on the other hand, $23.23 \%$ were hepatobiliary disorders. Gastrointestinal disorders presented $12 \%$ of the cases, followed by general disorders and administration site conditions, immune system disorders, and nervous system disorders with $7.8 \%, 5.56 \%$, and $4 \%$ of the cases (as illustrated in Figure 3).

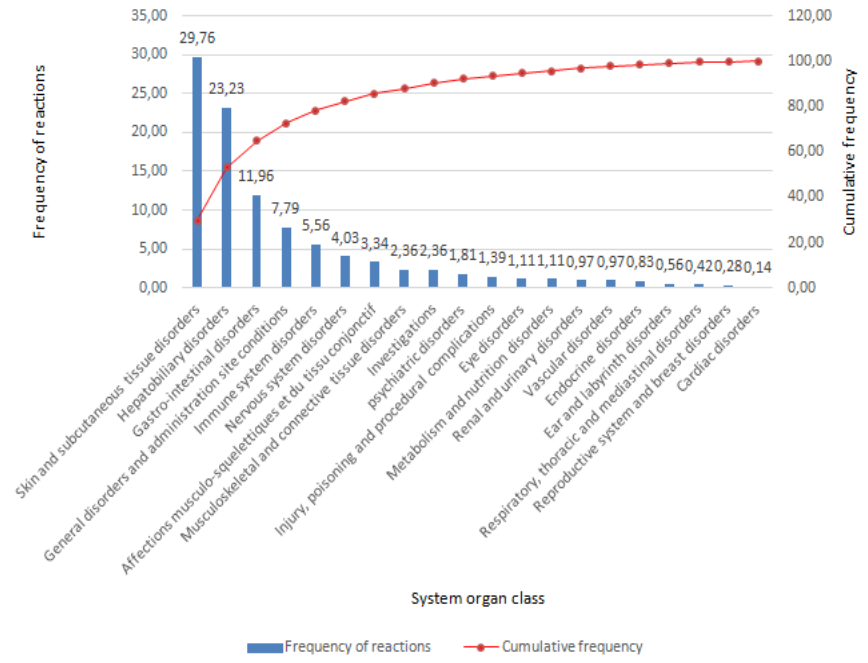

Figure 3: Pareto diagram: Distribution of the ADRs $(n=1160)$ according to the organ system achieved $(\mathrm{p}<0.0001)$

Figure 4 portrays the distribution of $90 \%$ of ADRs according to the organ system affected and the ATC class of the involved anti-infective drugs for systemic use:

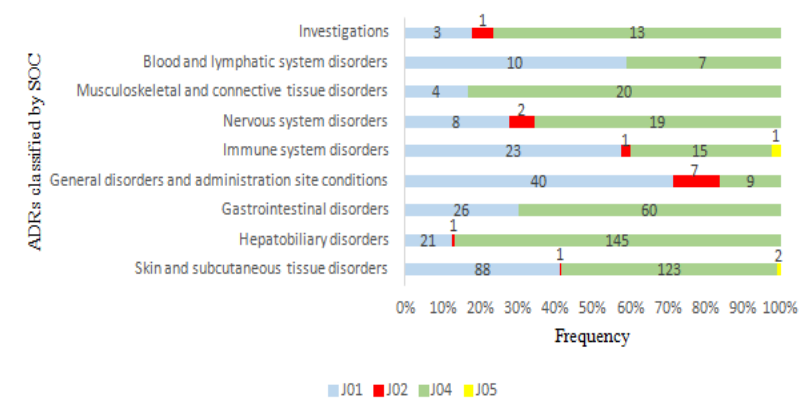

Figure 4:Distribution of ADRs by the organ system class according to ATC class of anti-infective drugs for systemic use involved $(\mathrm{p}<0.0001)$

The antimycobacterians (Class ATC J04) have been responsible mainly for:

- $86.83 \%$ of hepatobiliary disorders

- $83.33 \%$ of musculoskeletal and connective tissue disorders

- $76.47 \%$ of investigations

- $69.77 \%$ of gastrointestinal disorders

- $65.52 \%$ of nervous system disorders

- $57.48 \%$ of skin and subcutaneous tissue disorders

- $41.18 \%$ of blood and lymphatic system disorders 
- $37.50 \%$ of immune system disorders

- $16.07 \%$ of general disorders and administration site conditions.

Antibacterials for systemic use (class ATC J01) were

liable for: $71.43 \%$ of general disorders and administration site conditions, and $58.82 \%$ of blood and lymphatic system disorders, While, Antimycotics for systemic use (ATC Class J02) were accountable for: $12.50 \%$ of the general disorders and administration site conditions.

Severe cases depicted $30 \%$ of the studied cases (156 cases), with hospitalization or prolongation of hospitalization in $66,7 \%$ of cases, life threatening in $3.9 \%$ of cases, $0.7 \%$ of cases were subject to disabilities and $5.8 \%$ of cases died (as showcased in Figure 5).

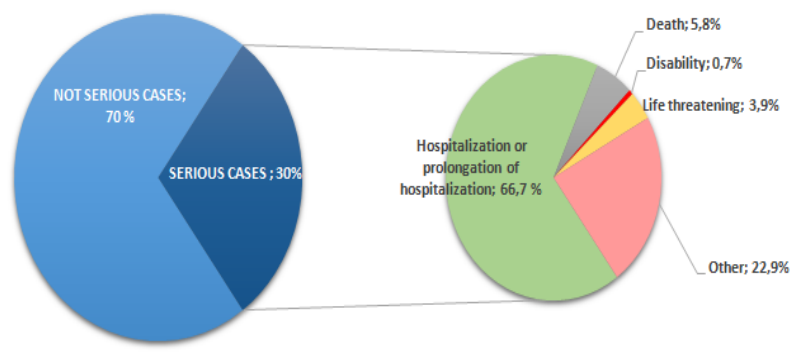

Figure 5: distribution of cases $(n=520 / 1160)$ according to the severity criteria of the ADRs

$(\mathrm{p}<0.0001)$

In the "serious" cases of ADRs, antibacterials for systemic use (Class ATC J01) and antimycobacterials (Class ATC J04) were the main incriminated drugs (Figure 6). These two therapeutic classes were the only ones to cause deaths.

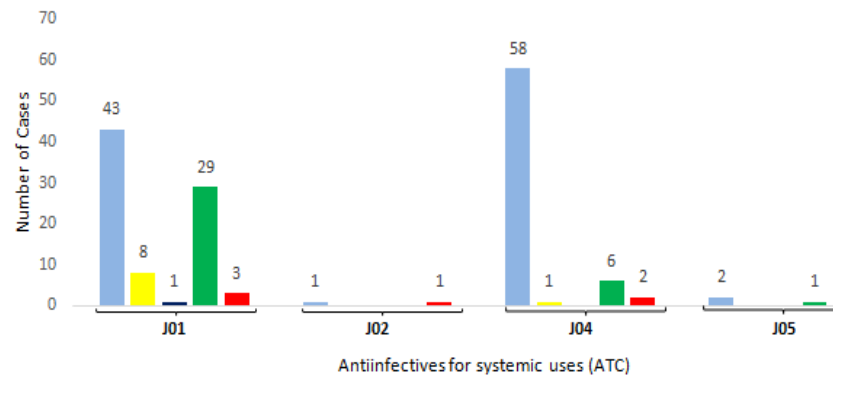

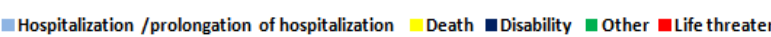

Figure 6: Criteria of case's severity $(n=156 / 1160)$ of reported ADRs Classified by class of involved anti-infective drugs for systemic use $(\mathrm{p}<0.0001)$

Figure 7 shows the distribution of ADRs cases of antiinfective drugs for systemic use according to the evolution of their health status. The evolution was favorable in $91 \%$ of the cases. Unrecovered cases and cured with sequelae accounted for $6 \%$ and $1 \%$ respectively. A set of 9 cases died, representing $2 \%$ of all cases.

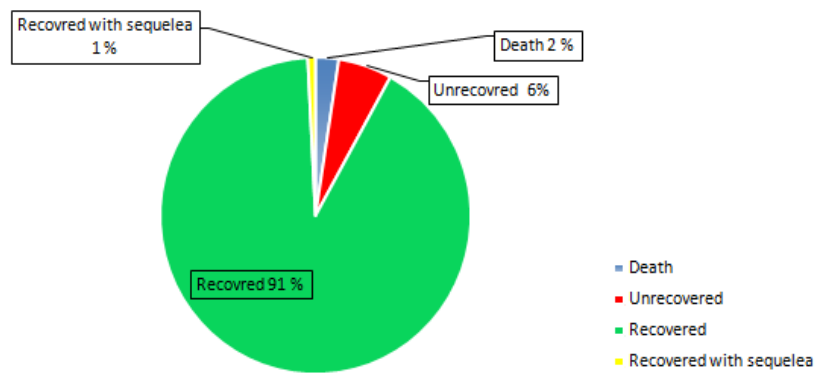

Figure 7: Distribution of cases $(n=373 / 1160)$ according to health status $(\mathrm{p}<0.0001)$

\section{Discussion}

Anti-infective drugs for systemic use, employed for their therapeutic benefits, are associated with inevitable risks of adverse drug reactions, shifting from very minor to extremely severe and rarely fatal [9]. On top of that, antibiotics are considered to be the main group of drugs causing ADRs worldwide [3]. As matter of fact, according to the World Health Organization (WHO), an adverse reaction is a harmful and unwanted reaction suspected to be attributable to a drug [10].

The spontaneous reports represent the cornerstone of any pharmacovigilance system, based on these reports, pharmacovigilance centers are able to detect adverse effects and generate signals on a much larger scale. That's why it is regarded as the fundamental method for detecting adverse drug reactions [11].

A study dating from 2009, details that ADRs are underreported in developing countries compared to the developed ones [12]. These reports are now reinforced in Africa by the creation of national pharmacovigilance 
centers in Morocco, Nigeria, South Africa, Zimbabwe, and Ghana [13]. Furthermore, healthcare professionals and patients are subsequently encouraged to declare ADRs to these centers [14] [15]. During the period of our inquest, a total of 1,161 cases of adverse reactions resulting from infectious agents for systemic use were disclosed to the Moroccan pharmacovigilance center.

As stated by various researches, ADRs are an important cause of hospitalization, with a variant proportion of $0.9 \%$ to $7.9 \%$ [16], thereby confirming our results indicating that hospitalization or prolongation of hospitalization represents $66,7 \%$ of the cases due to treatment by anti-infectives for systemic use.

Of the entire reported cases; $81.89 \%$ were adults, which might be explained by a number of factors such as: excessive taking of antibiotics, self-medication, the use of a defective or even poor quality product as well as consuming too many drugs at once, (the average number of drugs administered was 1.81 and $2 \%$ of the subjects were taking several drugs at basically the same time). Consequently, of all the declared ADRs, 10 antiinfective for systemic use were incriminated by concomitant consumption, and three had badly interacted with other drugs.

The patients' sex ratio was 1.34 in favor of the female sex, which is consistent with studies corroborating that sex is a critical and influential risk factor for adverse reactions of medication. Both in hospitals and in communities, women are 1.5 to 1.7 times more likely than men to experience ADRs, including skin reactions [17].

In January 2001, the US General Accounting Office informed the United States House of Representatives and the Senate that out of 10 prescription drugs withdrawn since January 1997, eight were more dangerous for women than for men. For four out of these eight drugs, this phenomenon could be explained by greater utilization among women. The other remaining (four) drugs, nonetheless, were more risky for women while being generously prescribed for both sexes. Concerning these four drugs, the report concluded, that the increased health risk for women could be attributed to physiological features that made them more likely to have adverse reactions to certain drugs [18].

Amongst $90 \%$ of the declared ADRs, $29.76 \%$ of them were skin and subcutaneous tissue disorders on the other hand $23.23 \%$ of the cases were hepatobiliary disorders. Gastrointestinal disorders equated $12 \%$ of the cases, while general disorders and administration site conditions, immune system and nervous system disorders represented respectively $7.8 \%, 5.56 \%$ and $4 \%$ of the total cases.

Our results are in perfect accordance with a study examining the adverse drug reactions of all the antibiotics' classes communicated to a peripheral pharmacovigilance center in India over a period of three years, and which showed that dermatological adverse effects $(47,4 \%)$ and gastrointestinal $(39.3 \%)$ were the most common [19]. What's more, an eight-year retrospective study on side reactions to antibiotics amassed by a pharmacovigilance center in Korea reveals that the cutaneous manifestation was the most recurrent, followed by hematological and neurological manifestations [12].

The present results demonstrate that, the most commonly recorded anatomical, therapeutic and chemical classes were antimycobacterials (Class ATC J04) in $68.02 \%$ of the cases and anti-bacterials for systemic use (Class ATC $\mathrm{J} 01$ ) in $28.36 \%$ of the cases. Indeed, among the "serious" ADRs, these two therapeutic classes were the only ones to bring about deaths.

Moreover, according to a retrospective study comparing the characteristics of spontaneous ADRs reports, and how it could have been avoided, from the regional pharmacovigilance databases of Bordeaux and national of Vietnam in 2015, antibacterials for systemic use (J01) were the most often involved [5]. Similar results were observed in a second study by Doan $\&$ al, where five out of six classes of the drugs most often implicated were systemic antibacterials (J01) [20].

The explanation for this can be attributed to the misuse of drugs (administration, dosage, duration of treatment, 
etc.) as well as allergic history, in particular drug allergies [21], in addition to self-medication, especially in the event of minor symptoms such as cough, sore throat, gastroenteritis and diarrhea [22]. Additionally, in Morocco, a cross-sectional descriptive study in 2010 showed a prevalence of self-medication of $77.67 \%$, of which $53.76 \%$ were used by women [23].

\section{Conclusion}

On the subject of preventing ADRs risks resulting from using anti-infective drugs for systemic use, whether being a potential risk or proven one, it is crucial to proceed towards the application of pharmacovigilance systems which fundamentally depends on spontaneous reporting of adverse drug reactions, for the sake of determining the danger profiles linked to medicinal products and detecting rare or unidentified reactions associated to their consumption.

\section{Acknowledgments}

The authors are pleased to acknowledge the Moroccan Anti-poison and Pharmacovigilance Center MAPPC for providing the facilities for the research. Along with the entire research team of: the Laboratory of Genetics and Biometry at Ibn Tofail University. This work was carried out within the framework of the Priority Project PPR-BMokhtari-FS-UIT Kenitra, Morocco.

\section{References}

1.Centers of Disease Control and Prevention. Antibiotic resistance threats in the United States. U.S. department of health and human services, United States. [2013] ; pp : 31-57.

2.Schlemmer B. Régulation de l'utilisation des antibiotiques : objectifs, moyens et perspectives Éditions scientifiques et médicales Elsevier SAS. Annales Françaises d'Anesthésie et de Réanimation . Vol.19, Issue 5, [May 2000], 403-408 .

3.Young-MinYe MD, PhD, SeungKwanLimMD,Young-Wha Choi MD, PhD,So-Hee Lee MD, Ji-Ho Lee MD,Seung-Hee Park ,Lee Young-Hee. Adverse drug reactions to antibiotics collected by a pharmacovigilance center in Korea: an eightyear retrospective study.Journal of Allergy and Clinical Immunology, suppl. S; St. Louis Vol. 141, $\mathrm{N}^{\circ} 2$, (Feb 1, [2018]: AB87.

4.Rouveix B. Antibiotic safety assessment. Int $J$ Antimicrob Agent [2003];21:215-21.

5. DUONG.K. Evaluation de l'évitabilité des effets indésirables médicamenteux à partir des bases de données de pharmacovigilance de bordeaux et du vietnam (PREVENT -ASRs),Pharmacovigilance ,Bordeaux ,Université de Bordeaux [2017],70

6.E. Polard, La pharmacovigilance des antibiotiques Exemples de quelques effets indésirables rapportés avec les bêtalactamines, les fluoroquinolones, les macrolides et les cyclines ,La Lettre de l'Infectiologue - Tome XX $\mathrm{n}^{\circ} 6$ - [novembre-décembre 2005] .

7.Lefébre L, Mathieu M, Nantel A, Rambourg SM. Définitions INTOX. [Mars2000]

8. Donner.A , Banting.D. Adjustment of Frequently Used Chi-square Procedures for the Effect of Site-to-Site Dependencies in the Analysis of Dental Data. J Dent Res [1989] 68(9):1350-1354.

9.Curtin F., Schulz P. Assessing the benefit: risk ratio of a drug-randomized and naturalistic evidence. Dialog Clin Neurosci. [2011];13(2):183-90.

10.World Health Organization ,UMC Glossary Disponible on https://www.who-umc.org/globalpharmacovigilance/global-pharmacovigilance/glossary/ [Consulted on 09/06/2018].

11.Montastruc J- L,Sommet A, Lacroix I, Olivier P, Durrieu G, Damase-Michel C, ... et Bagheri H[2006].. $\mathrm{La}$ pharmacovigilance et l'évaluation $\mathrm{du}$ risque médicamenteux: intérêt, fonctionnement et méthodes. Revue du rhumatisme vol. 73, no 10, p. 10211024., [2006].

12. Oshikoya KA, Awobusuyi JO. Perceptions of doctors to adverse drug reaction reporting in a teaching hospital in LagosNigeria. BMC Clin Pharmacol [2009] 9: 14..

13.World Health Organization Programme Members. Countries participating in the WHO Programme for International Drug Monitoring, with year of joining. 
Disponible on http://www.whoumc.org/DynPage.aspx?id=100653\&mn1 = 7347\&mn2 $=7252 \& \mathrm{mn} 3=7322 \& \mathrm{mn} 4=7442$ [Consulted on 09/06/2018]

14.Oshikoya KA. Treating children for malaria fever in theface of counterfeit and fake medicines. Int J Med Med Sci [2010] . 2:1-2.

15.NAFDAC. National Agency for Food and Drug Administration and Control NAFDAC Act.2016]. Disponible on http://www.nafdac.gov.ng/index.php/aboutnafdac/nafdac-act . [Consulted on 02/03/2018 ]. 16.Olivier P,BoulbésO,Tubery M, Lauque D, MontastrucJL,Lapeyre Mestre M,Assessing the Feasibility of Using an Adverse Drug Reaction Preventability Scale in Clinical Practice. Drug Saf[2002] ;25:1035-44

17.Rademaker, M., Do women have more adverse drug reactions? Am J Clin Dermatol [2001]; 2 (6): 349-51.

18.Drug Safety: Most Drugs Withdrawn in Recent Years Had Greater Health Risks for Women, United States General Accounting Office Washington, DC, GAO 01286R.

19.Richa Tandon V R, Sharma S, Khajuria V, Mahajan V, GillaniZ. Adverse drug reactions profile of antimicrobials: a 3-year experience, from a tertiary care teaching hospital of India.Indian $J$ Med Microbiol [2015] 33: 393-400

20.DOAN TP ,TRAN T, VU D ,NGUYEN H ; Identification of preventable adverse drug reaction on the Vietnamese Pharmacovogolance Database : A retrospective Analysis .Bangkok, Thailand : The first international conference on pharmacy education and reseach Network of ASEAN ( ASEAN PharmNET I) ; [2015] déc . [Consulted on 02/04/2018 http://canhgiacduoc.org.vn/SiteData/3/UserFiles/Poster\% 20Thao\%20(1).pdf]

21.Bandekar MS ,Anwikar SR , Kshirsagar NA .Quality check of spontaneous adverse drug reaction reporting forms of different countries, phamacoepidemiol Drug Saf $[2010] ; 19 ; 1181-5$
22.Van Duong D,Binns CW, Van Le T Availability of antibiotics as over the counter drugs in pharmacies : a threat to public health in Vietnam .Trop Med Int Health TM IH [1997];2;1133-9

23. EL YALLOULI EL IDRISSI, Elmehdi. La pratique de l'automédication : enquête dans la ville de Fès au Maroc. Thése de pharmacie, Rabat, Université mohamed $V[2016] ;, 125$ 